\title{
Properties of a HTS magnet consisting of pancake windings by using the $E-J$ method
}

\author{
Youngmin Kim, Myunghun Kang, Kyoung-ho Paik, Gueesoo Cha*, Changwan Jeon \\ Soonchunhyang University, Asan 336-745, Korea
}

Received 25 October 2011; accepted 23 November 2011

\begin{abstract}
In a High temperature superconducting (HTS) tape with high aspect ratio, the magnetic field applied to the HTS tape can be different considerably within the HTS tape. The current distribution in the HTS tape is generally non-uniform because the current distribution is strongly dependent on the applied magnetic field. Non-uniform current distribution in a HTS tape has not been properly considered when the critical current has been estimated. This paper shows the calculation of critical current of a HTS magnet consisting of pancake windings. Non-uniform distribution of current in the HTS tape is considered during the calculation of the critical current. Results of calculation show the current concentrated in the middle part of the HTS tape which is used for one pancake winding.
\end{abstract}

\section{INTRODUCTION}

A number of superconducting machines are being developed, such as, SMES (Superconducting Magnetic Energy Storage), NMR (Nuclear Magnetic Resonance), MRI (Magnetic Resonance Image) and magnetic separator [1-3]. Superconducting magnets are used for most of the superconducting machines. To guarantee the cryogenic stability of the superconducting magnets, it is important to estimate precisely the critical current of the superconducting magnets.

In a HTS tape which is used for the HTS magnet with high aspect ratio, the magnetic field applied to the HTS tape can be different considerably within the HTS tape. The current distribution in the HTS tape is generally non-uniform because current distribution is strongly dependent on the applied magnetic field. In order to estimate the critical current of the HTS magnet, it is needed to consider the non-uniform distribution of the current in the HTS tape. Non-uniform current distribution in a HTS tape has not been considered when the critical current has been estimated. Current distribution in a HTS tape has been studied in some papers $[4,5]$.

This paper shows the current distribution in the BSCCO-2223 tape which is used to wind a HTS magnet. Current distribution in the HTS tape of a pancake winding and stack of three pancake windings are calculated. Inner and outer diameter of the pancake windings are $40 \mathrm{~mm}$ and $74.5 \mathrm{~mm}$, respectively. Number of turns of the pancake winding is 50 turns.

\footnotetext{
* Corresponding author: gsoocha@sch.ac.kr
}

Electric fields generated in each turn of a pancake winding are presented. The critical current of the magnet are determined by using the electric field generated in each turn. Results of calculation show that current distribution in the HTS tape differs considerably from point to point within the HTS tape.

\section{ANALYSIS MODEL}

BSCCO-2223 tape is employed as the HTS tape for the HTS magnet in the analysis model. Specifications of the BSCCO-2223 tape are shown in Table 1. Critical current at self-field, $77 \mathrm{~K}$ is $126 \mathrm{~A} .1 \mu \mathrm{V} / \mathrm{cm}$ is the criterion used to determine the critical current. The width and the thickness of the BSCCO-2223 tape are $4.4 \mathrm{~mm}$ and $0.285 \mathrm{~mm}$, respectively.

$I_{\mathrm{c}}-B$ relation and the $n$-value of the BSCCO-2223 tape are shown in Fig. 1, which are obtained from the Reference 6. To obtain the angle-dependent $I_{\mathrm{c}}-B$ relation and the $n$-value, angle of the magnetic field was changed from $0^{\circ}$ to $90^{\circ}$. Magnetic field of $90^{\circ}$ means the perpendicular magnetic field which is applied to the wide face of the HTS tape. When the angle is $0^{\circ}$, the $n$-value decreases from 20.7 to 6.1 as the applied magnetic field increases from $0 \mathrm{~T}$ to $0.8 \mathrm{~T}$. At the same condition except the angle is $90^{\circ}$, the $n$-value decreases from 11.8 to 1.2 .

Table 2 shows the specifications of the HTS magnet. Number of turns and total length of a pancake winding is 50 turns and $8.98 \mathrm{~m}$. Two types of HTS magnet are considered ; 1) one pancake winding, 2) three pancake windings. Insulation tape whose thickness is $60 \mu \mathrm{m}$ is inserted between the turns of the pancake winding. Inner and outer diameter of a pancake winding are $40 \mathrm{~mm}$ and $74.5 \mathrm{~mm}$, respectively. No gap is considered between the pancake windings at stack of three pancake windings.

TABLE I

SPECIFICATIONS OF THE HTS TAPE.

\begin{tabular}{cc}
\hline Type of HTS tape & BSCCO-2223 \\
Ic (77 K, self-field) & $126 \mathrm{~A}$ \\
Width & $4.4 \mathrm{~mm}$ \\
Thickness & $0.285 \mathrm{~mm}$ \\
Min. bending diameter & $38 \mathrm{~mm}$ \\
\hline
\end{tabular}




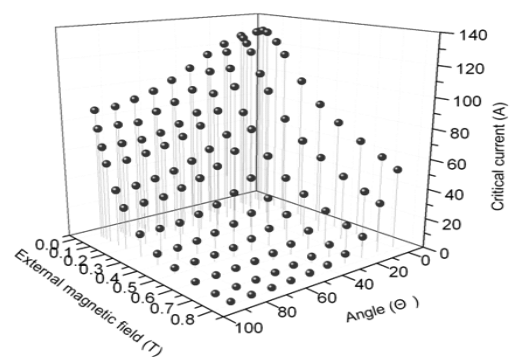

(a) $I_{\mathrm{c}}-B$ relation

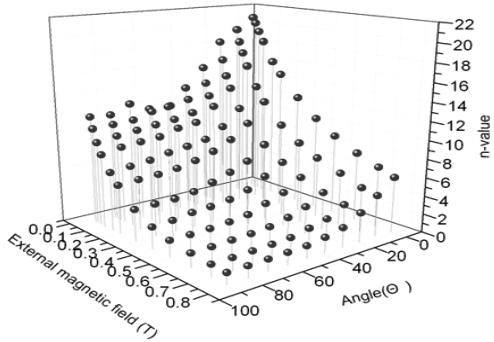

(b) $n$-value

Fig. 1. $I_{\mathrm{c}}-B$ relation and the $\mathrm{n}$-value of the $\mathrm{BSCCO}-2223$ tape.

TABLE II

SPECIFICATIONS OF THE HTS MAGNET.

\begin{tabular}{cc} 
SPECIFICATIONS OF THE HTS MAGNET. \\
\hline Inner diameter & $40 \mathrm{~mm}$ \\
Outer diameter & $74.5 \mathrm{~mm}$ \\
No. of pancake windings & 1,3 \\
No. of turns per pancake winding & 50 \\
Length of a pancake winding & $8.98 \mathrm{~m}$ \\
Insulation thickness & $60 \mu \mathrm{m}$ \\
\hline
\end{tabular}

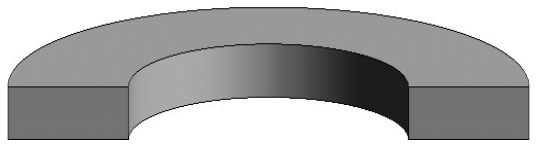

(a) one pancake winding

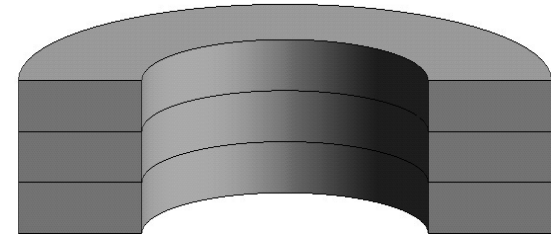

(b) three pancake windings

Fig. 2. Structure of HTS magnet.

Fig. 2 shows the schematic view of the magnet used for the calculation of current distribution in the HTS tape and the critical current of the HTS magnet.

\section{CALCULATION METHOD}

Critical current of the BSCCO-2223 magnet can be estimated from the $V-I$ relation of the pancake winding to which maximum perpendicular magnetic field is applied.
Only the $V-I$ relation of the outermost pancake winding is needed to determine the critical current of the pancake windings. This is because the critical current is determined by the current of the outermost pancake winding to which the maximum perpendicular magnetic field is applied. In order to obtain the $V-I$ relation of the pancake winding, generated voltage of the pancake winding at some operating currents is calculated.

During the calculation of generated voltage, non-uniform current distribution in the HTS tape is considered. To consider the non-uniform current distribution, the width of tape is divided into $M$ elements and the current of each segment is calculated. $I_{\mathrm{c}}-B$ relation and the $n$-value are used to calculate the current of each segment. Orientation of applied magnetic field to the HTS tape is also considered when the critical current is calculated.

The voltage in each turn at a specific operating current is calculated from the critical current and operating current of the pancake winding by using power-law [7]. $V$ - $I$ relation can be obtained from the generated voltages at several operating currents.

The procedure to calculate the voltage across the pancake winding with respect to an operating current is described below.

An operating current is selected and the generated voltage at the operating current is calculated. The lowest operating current should be smaller the expected critical current. The cross-section of the HTS tape is divided into $\mathrm{M}$ segments. Initial current of all elements is assumed as the constant value, that is, a constant current is assigned to each element of the HTS tape. The magnetic field which is applied to each element in the HTS tape is calculated to obtain the magnitude and direction of the applied magnetic field.

The critical current can be calculated from the magnitude and direction of applied magnetic field and the angle-dependent $I_{\mathrm{c}}-B$ relation shown in Fig. 1.(a). The $n$-value can be also obtained from the magnitude and direction of applied magnetic field and the angle-dependent $n$-value shown in Fig. 1.(b). A voltage which is generated in a turn is assumed. This voltage is an initial voltage which is needed to find the actual voltage.

The critical current of each element is calculated by using power-law. The sum of all element currents has to be equal to the operating current. If the difference between the sum of all element currents and the operating current is larger than the pre-determined error $\left(10^{-3} \mathrm{~A}\right)$, then the voltage in a turn is changed and the above process is continued. If difference is smaller than the pre-determined error, the generated voltage of the pancake winding is calculated. The generated voltage of the pancake winding is the sum of the generated voltage of each turn.

If the difference between the previously calculated voltage and the newly calculated voltage is larger than the pre-determined error $\left(8.9 \times 10^{-11} \mathrm{~V}\right)$, the current of each element is changed to new value. If the difference is smaller than the pre-determined error, the current of each element is thought to be the current distribution in a HTS tape at that 
operating current. This is the end of the calculation of the generated voltage at one operating current.

If the generated voltage at an operating current is larger than the voltage criterion which is obtained with $1 \mu \mathrm{V} / \mathrm{cm}$ criterion, the operating current is thought to be larger than the critical current. If the generated voltage at an operating current is smaller than the voltage criterion, the operating current is thought to be smaller than the critical current. The highest operating current at which generated voltage is calculated should be larger than the expected critical current. Exact critical current can be calculated by using iteration.

\section{CALCULATION RESULTS}

At the HTS magnet consisting of one pancake winding (Fig. 2.(a)), generated voltage of the HTS magnet is calculated at 6 operating currents, that is, every 10 A from $45 \mathrm{~A}$ to $95 \mathrm{~A}$. The electric field generated in each turn is shown in Fig. 3.(a). The electric field at $95 \mathrm{~A}$ is not shown in Fig. 3.(a) because its magnitude is too large comparing with other electric field. The electric field shows a peak at the 38th turn because the magnitude of perpendicular magnetic field is maximum at the 38th turn. When the operating current is $85 \mathrm{~A}$, the electric field of the most turns is larger than the criterion of $1 \mu \mathrm{V} / \mathrm{cm}$. When the operating current is $75 \mathrm{~A}$, the electric field of the most turn is lower than the criterion of $1 \mu \mathrm{V} / \mathrm{cm}$. From the results, the critical current will be between $75 \mathrm{~A}$ and $85 \mathrm{~A}$.

At the HTS magnet stacking of three pancake windings, generated voltage of the HTS magnet is calculated at 6 operating currents, that is, every $5 \mathrm{~A}$ from $35 \mathrm{~A}$ to $60 \mathrm{~A}$. The electric field generated in each turn of the outermost pancake winding is shown in Fig. 3.(b). Only the electric field of the outermost pancake winding is shown in Fig. 3, because the highest electric field is generated in the outermost pancake winding.

The turn which has the highest electric field changes as the operating current varies at the stack of three pancake windings. The electric field shows a peak at around 38th turn in this case. When the operating current is $55 \mathrm{~A}$, the electric field of the most turn is larger than the criterion of 1 $\mu \mathrm{V} / \mathrm{cm}$. When the operating current is $50 \mathrm{~A}$, the electric field of the most turn is lower than the criterion of $1 \mu \mathrm{V} / \mathrm{cm}$. According to the results, the critical current will be between $50 \mathrm{~A}$ and $55 \mathrm{~A}$.

Fig. 4 shows the current distribution in the HTS tape. Cross-section of the HTS tape is divided into 10 elements. Considering the cross-section of the HTS tape is $4.4 \times 0.285$ $\mathrm{mm}^{2}$, cross-section of an element is $0.44 \times 0.285 \mathrm{~mm}^{2}$. In one pancake winding (Fig. 4.(a)), the current in the middle elements (element 5 and 6) is larger than the current in the outer elements. When the operating current is $75 \mathrm{~A}$, the current of elements $1-5$ are $6.02,6.54,7.20,8.13,9.61 \mathrm{~A}$, respectively. The current of elements $6-10$ are the same with the current of elements 5 - 1 because of symmetry.

In a HTS magnet stacking of three pancake windings (Fig. 4.(b)), the current of each pancake winding shows different distribution according to the geometric location.

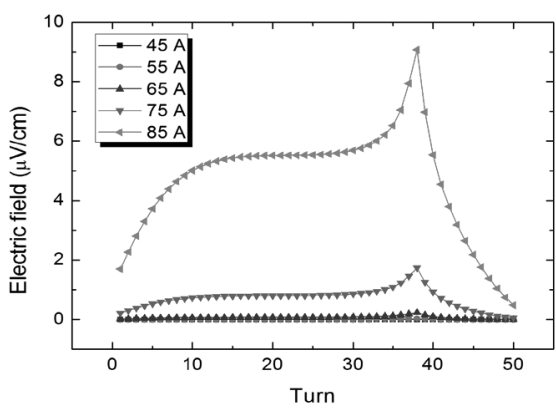

(a) one pancake winding

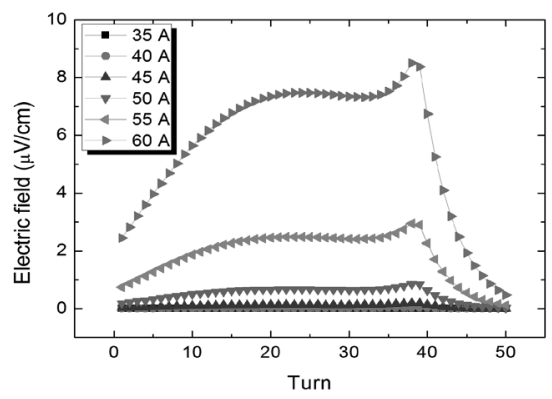

(b) three pancake windings

Fig. 3. Electric field generated in each turn.

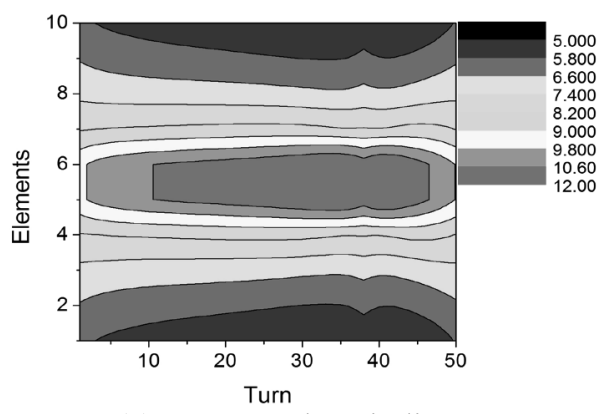

(a) one pancake winding

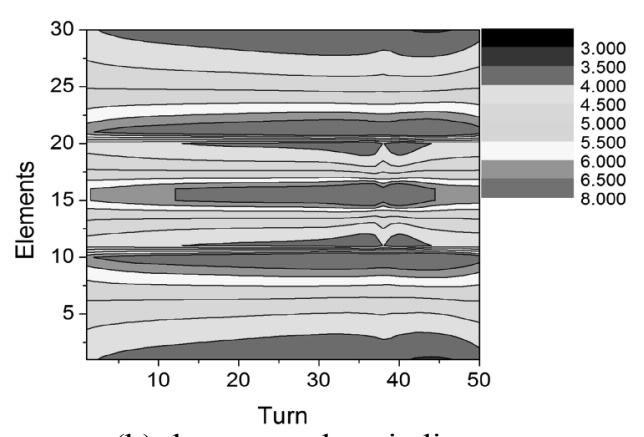

(b) three pancake windings

Fig. 4. Current distribution in the HTS tape.

In the upper pancake winding (element 21 - 30), the bottom element (element 21) has the highest current. In the lower pancake winding (element 1-10), the top element (element 10) has the highest current. In the middle pancake winding (element 11-20), middle elements (element 15 and 16) have the highest currents. When the operating current is $50 \mathrm{~A}$, the currents of elements 1 - 10 (lower pancake winding) are $4.11,4.25,4.39,4.55,4.74,4.96,5.21,5.52,5.89,6.39 \mathrm{~A}$, 
TABLE III

Generated Voltage at SeVEral Operating CurRents.

\begin{tabular}{cccc}
\hline \multicolumn{2}{c}{1 pancake winding } & \multicolumn{2}{c}{3 pancake windings } \\
Current $(\mathrm{A})$ & Voltage $(\mu \mathrm{V})$ & Current $(\mathrm{A})$ & Voltage $(\mu \mathrm{V})$ \\
\hline 45 & 0.11 & 40 & 13.97 \\
55 & 3.78 & 45 & 92.15 \\
65 & 64.34 & 50 & 441.95 \\
75 & 640.42 & 55 & 1643.58 \\
85 & 4189.84 & 60 & 4981.03 \\
95 & 19732.92 & 65 & 12778.82 \\
\hline
\end{tabular}

respectively. The currents of elements 11 - 15 (lower elements of middle pancake winding) are 4.25, 4.54, 4.89, 5.35, 5.97 A, respectively. The current of elements $16-30$ are the same with the current of elements $15-1$.

The generated voltage at several operating currents is summarized in Table 3. Considering the total length of a pancake winding is $8.98 \mathrm{~m}$ and the criterion of the critical electric field is $1 \mu \mathrm{V} / \mathrm{cm}$, critical voltage of the magnet is set to $898 \mu \mathrm{V}$. From Table 3, the critical current of the one pancake winding is between $75 \mathrm{~A}$ and $85 \mathrm{~A}$. The critical current of the stack of three pancake windings is between $50 \mathrm{~A}$ and $55 \mathrm{~A}$. The critical current of the HTS magnet consisting of one pancake winding and three pancake windings are $75.7 \mathrm{~A}$ and $51.9 \mathrm{~A}$, which are obtained by using iteration method.

\section{CONCLUSION}

When the applied magnetic field to the HTS tape is not uniform, current distribution in a HTS tape is not uniform.
Critical current of the one pancake winding and three pancake windings was calculated in this paper, where the non-uniform current distribution was considered.

Results of calculation show non-uniform current distribution in a HTS tape. For example, current concentrated in the middle part of the HTS tape at a HTS magnet consisting of one pancake winding. The accuracy of critical current estimation could be increased by considering the non-uniform distribution of the current in a HTS tape.

\section{REFERENCES}

[1] K. Shikimachi et al., "Development of MVA class HTS SMES system for bridging instantaneous voltage dips," IEEE Trans. Appl. Supercond., vol.15, pp. 1931-1934, 2005.

[2] T. Kiyoshi et al., "Operation of a 930-MHz high-resolution NMR magnet at TML," IEEE Trans. Appl. Supercond., vol.15, pp. 1330-1333, 2005.

[3] M. Sekino et al., "Fabrication of an MRI Model Magnet With an Off-Centered Distribution of Homogeneous Magnetic Field Zone," IEEE Trans. Appl. Supercond., vol.20, pp. 781-785, 2010.

[4] A. Miyazoe et al., "Current distribution in coated conductor under external magnetic field up to 5T," IEEE Trans. Appl. Supercond., vol.21, pp. 1600-1603, 2011.

[5] Y. Adanny et al., "Calculated E-I characteristics of HTS pancakes and coils exposed to inhomogeneous magnetic fields," J. Phys.: Conf., Ser. 43, pp. 1068-1071, 2006.

[6] Y. Kim et al., "Properties of High Temperature Superconducting Magnet With Optimized Air Gap Between Pancake Windings,' IEEE Trans. Appl. Supercond., vol.21, no.3, pp.2267-2270, 2011.

[7] J. Zhang et al., "The Electromagnetic Analysis and Structural Design of a 1 MJ HTS Magnet for SMES," IEEE Trans. Appl. Supercond., vol. 21, pp. 1344-1347, 2011 